\title{
The Effect of Prices and Income on Car Travel in the UK
}

\author{
Joyce Dargay \\ ESRC Transport Studies Unit \\ Centre for Transport Studies \\ University College London
}

February 2004

For presentation at the World Conference on Transport Research

Istanbul, Turkey, July 2004 


\title{
The Effect of Prices and Income on Car Travel in the UK
}

Joyce Dargay, ESRC Transport Studies Unit, Centre for Transport Studies, UCL, Gower Street, LONDON, WC1E6BT e-mail: j.dargay@ucl.ac.uk

\begin{abstract}
The objective of this paper is to analyse the factors determining household car travel, and specifically the effects of household income and the prices of cars and motor fuels, and to explore the intertemporal pattern of adjustment. The question of asymmetry in the response to rising and falling income is also addressed. Such asymmetry may be caused by habit or resistance to change or the tendency to acquire habits to consume more easily than to abandon them. The impact of prices, the speed of adjustment and the resistance to change will be important in determining the possibility of influencing travel behaviour and specifically car use. The study utilises repeated cross-section data from the annual UK Family Expenditure Surveys and employs a pseudo-panel methodology. The results are compared with those for car ownership estimated on the basis of similar models.
\end{abstract}

\section{Keywords: pseudo-panel data, car use, travel demand modelling, price elasticities}

\section{Topic area: D1 Passenger Transport Demand Modelling}

\section{Introduction}

Understanding the historic evolution of travel patterns and the response to changes in circumstances and economic factors is a necessary component in projecting future travel demand and assessing the influence of policy measures. Because of the pervasiveness of habits, inertia, imperfect information, etc., the response to changes in income, personal circumstances, transport supply and prices does not occur instantaneously, but takes place over time. Similarly, individual households' travel patterns change over the life cycle and are different for different generations. Both of these factors imply a temporal instability which cannot be accounted for in equilibrium modelling. Thus in order to project demand or asses the impact of policy measures at a given period in time it is essential to have information concerning the intertemporal pattern of the adjustment process and the time scale required for this response.

The investigation of the intertemporal response of individuals to changes in their personal circumstances or to various policy measures requires dynamic modelling strategies based on observations of behaviour over time. Most commonly, two sorts of data are used for dynamic modelling: true panel data, i.e. surveys of the same individuals over time; and aggregate time-series data, made up of observations over comparatively long periods of time of relatively large groups of individuals, generally on a national or regional basis. Both of these have their shortcomings. Although time-series data are available for certain transport variables - car ownership, trips or kilometres travelled by various modes, etc. - over relatively long time periods, they are generally on a highly aggregate level. This limits the usefulness of such data for understanding individual behaviour: differences in 
between individuals and other underlying factors of importance for transport behaviour are lost in the aggregation process.

Panel surveys are clearly preferable since they trace the same individuals over time and can thus be used to model the dynamics of choice behaviour at the individual level. However, there are few transport panel surveys available, and those which do exist are of limited coverage both over time and geographically. The relatively short time periods available, combined with the problem of attrition limits the analysis of long-term behavioural changes and the effects of variables - such as costs - where the variation may be small over short time periods.

Repeated cross-section data provide a viable alternative. Such data are generally available for longer time periods than panel surveys, while providing more detailed information on individual behaviour and circumstances than is possible with aggregate time-series data. In the transport field, national travel surveys, which are carried out either annually or at regular intervals, are the most obvious examples. However, data collected for more general economic purposes, such as family expenditure surveys, can also be useful for analysing certain aspects of household transport.

There have been a number of examples of the use of repeated cross-section data in the transport literature. An early example is the demographic modelling of Madre (1990) This is based on age-period-cohort models in which "generation" and "life-cycle" effects are identified and used in conjunction with demographic forecasts for projecting car ownership and use. Dargay and Vythoulkas (1999) present the first attempt to use such data in the context of a dynamic econometric model. The study employs a pseudo-panel approach and UK Family Expenditure Survey (FES) data to relate car ownership to income, the costs of car ownership and use, public transport fares and socio-demographic characteristics. Using the same data, the effects of income and transport costs on car ownership in rural and urban areas is investigated in Dargay (2002) and the question of asymmetry in the relationship between car ownership and income is addressed in Dargay (2001). Dargay, Madre and Berri (2000) compare the demographic and dynamic econometric approaches in an application to car ownership in France and the UK.

This paper extends the pseudo-panel work on car ownership to analyse household car travel. It employs cohort data - defined in terms of the age of birth of the household head constructed from the UK Family Expenditure Surveys for the past two decades. Car travel is constructed from data on expenditures on motor fuels, using information on fuel prices and vehicle fuel efficiency. The model is dynamically specified by including a lagged dependent variable, so that both the short- and long-term effects of income and transport prices on car travel can be analysed.

In addition, the question of asymmetry in the response to rising and falling income is investigated. Such asymmetry, or hysteresis, may be caused by habit or resistance to change or addiction asymmetry - the tendency to acquire habits to consume more easily than to abandon them. This question is examined by using income decomposition techniques to separately estimate elasticities with respect to rising and falling income. The equality of these elasticities - no hysteresis - is tested statistically against the inequality hysteresis - hypothesis. The importance of hysteresis is that it is an indication of the difficulty of reversing the trend of increasing car use.

The paper begins with a description of the construction of the pseudo-panel data. In the following section, the car travel model and the specification of asymmetry are presented. The empirical results are presented and discussed in the remainder of the paper. 


\section{Construction of the pseudo-panel data}

The pseudo-panel data set is constructed from the annual UK Family Expenditure Surveys. This Survey has been carried out continuously since the 1960s and provides a random sample of around 7,200 households per year. Apart from expenditures on individual goods and services (including various transport expenditures), it provides information on household car ownership, income and socio-demographic characteristics.

The use of 'pseudo-panel' data was introduced by Deaton (1985) for the analysis of consumer demand systems. The pseudo-panels are formed by grouping households into cohorts on the basis of shared characteristics, and constructing the cohort variables as the average values for the households included. The cohorts are then traced over time in each of the annual surveys, forming a panel. Since the cohorts are followed over time, the characteristics chosen in forming the cohorts should be time-invariant. In grouping the individual households into cohorts, we lose information about the variation among households within each group so that estimates obtained on the basis of group means will generally be less efficient than estimates based on the individual data. This loss in efficiency will be minimised if the variation within cohorts is small compared with the variation between cohorts, so that cohorts including fewer, more similar, households will produce more efficient estimates. On the other hand, cohorts including a small number of households will result in less precise estimates of the cohort means. There is thus a tradeoff between the number of the cohort observations and the accuracy of these observations.

Cohorts can be defined in terms of a single characteristic or multiple characteristics. In this study, the cohorts are formed solely by the year of birth, or generation, of the household head. In order to ensure that the cohort means of the variables based on the sample are reasonable estimates of the population cohort variables, 5-year bands are used for defining the generations and only those cohorts containing at least 100 households are included in the statistical analysis. This results in 16 cohorts; the earliest having a household head born prior to 1900, and the most recent born between 1971 and 1975 .

Although car ownership for each of the cohorts can be taken directly from the household data in the FES, car travel must be constructed. This is done by using the FES data on expenditures on petrol and diesel, combined with annual data on fuel prices and vehicle fuel efficiency. The expenditures from each of the annual surveys (in £s per week) are divided by the average fuel price (in pence per litre) for the same year to obtain motor fuel consumption (in litres). Fuel use is then multiplied by the average on-road fuel efficiency for the car stock in the relevant year (in kms. per litre), thus resulting in a measure of car travel in terms of vehicle kilometres. In calculating car travel, it is assumed that, on average, each cohort faces the same fuel prices and operates vehicles of the same fuel efficiency at any point in time. Both fuel prices and fuel efficiency are consumption share weighted national averages of those for petrol and diesel. Of course, this will only be an approximation. Although fuel prices do not vary to any great degree amongst households, vehicle fuel efficiency does, so the differences in vehicle kms travelled between households will be understated. Similarly differences over time due to households' choosing vehicles of different efficiencies will also be understated. However, as the analysis is based on large groups of households with different characteristics, we could expect these differences to average out.

The resulting data on car travel for the cohorts over time are presented in Figure 1. Only every second cohort is shown for legibility. For comparison, car ownership for the same cohorts is given in Figure 2. The age of the household head is given on the horizontal axis, and car travel in kilometres per week on the vertical. The lines represent the different cohorts, with the birth-year bands given adjacent. The initial data point for each cohort is obtained from the first survey in which an observation for the cohort containing at least 
100 households is available, generally 1970, while the final data point is obtained from the last survey containing a comparable observation, generally 1995. For example, for the cohort labelled 1931-1935, the mean age of the head was 37 in the 1970 survey and 62 in the 1995 survey. The average household in this cohort owned about 0.75 cars and drove about 125 kilometres per week when the head was 37 years of age. Both car ownership and use increased until the head approached the age of 50, reaching a maximum of 1.2 cars and 225 kilometres, thereafter declining to 1 car and 175 kilometres by the age of 62 .

The diagrams show a similar pattern: a life-cycle effect - car ownership and use increase until the head is in his/her early $50 \mathrm{~s}$, and then decline; and a generation effect - at every 'age' car ownership and use are higher for more recent than for earlier cohorts.

Figure 1. Car travel, in kilometres per week, by cohort. 1970-95. Every second cohort shown with year-of-birth bands. UK FES data.

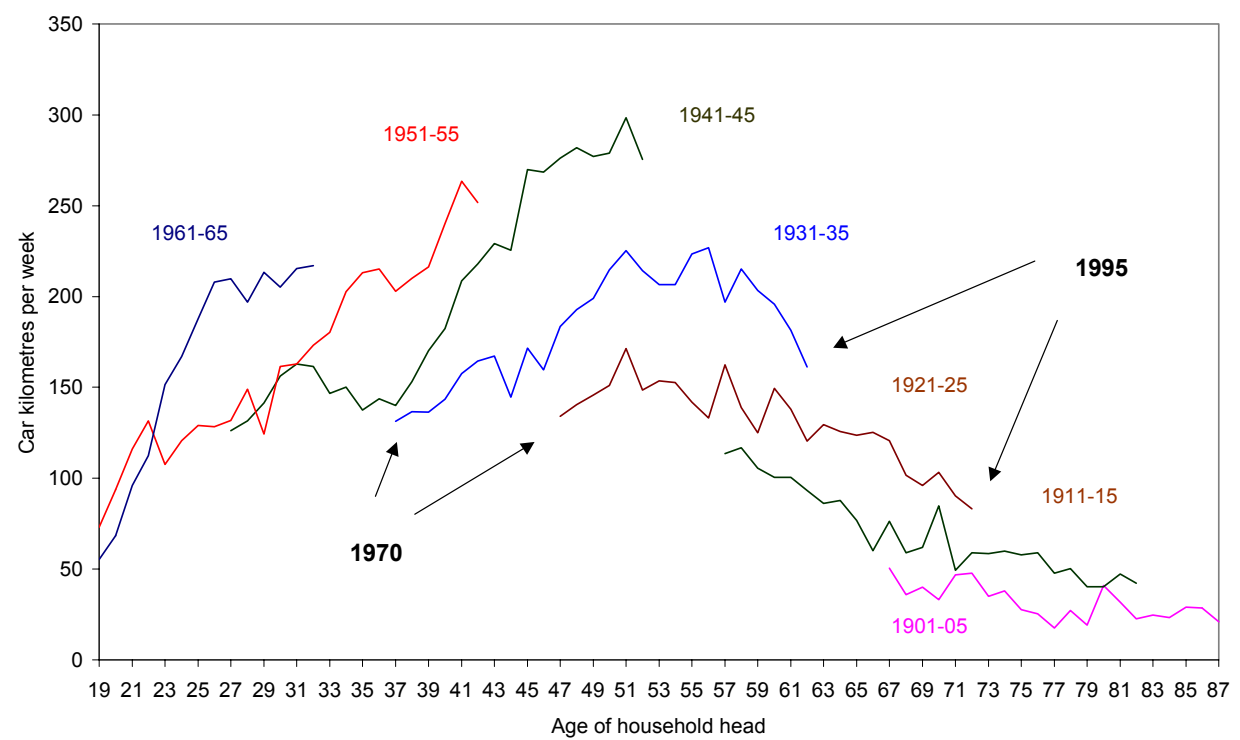

Figure 2. Car ownership by cohort. 1970-95. Every second cohort shown with year-of-birth bands. UK FES data.

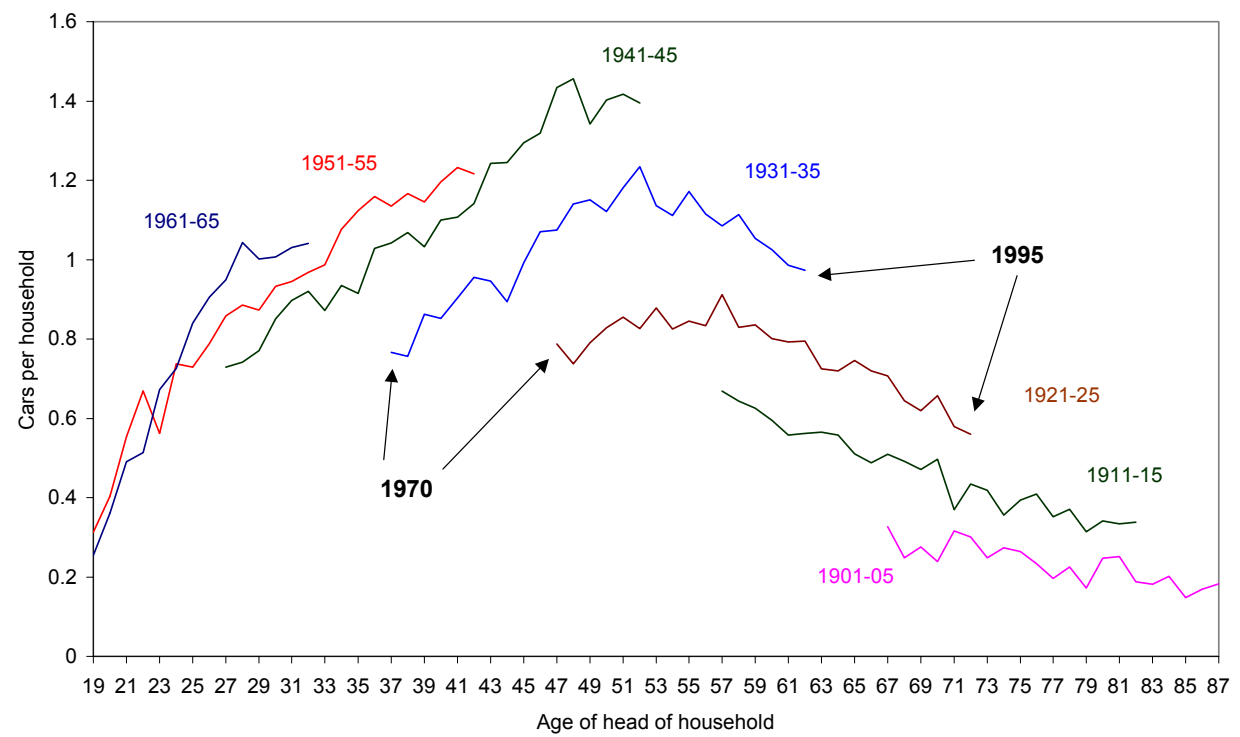


This pattern can partially be explained by differences in household income over the life cycle and differences in real income between generations. Real total expenditures (in $£$ s per week), used as a proxy for household income, display a similar pattern to that for car ownership and use. Total expenditures increase up until the head reaches his/her late 40s and decline thereafter. Similarly, at each age, real expenditures are higher for more recent generations. The generation effect for income, however, is not as pronounced as those noted for car ownership and use.

A similar life-cycle pattern can be noted for the number of adults per household. The average number of adults increases from less than 2 when the head is in his/her 20 s to a maximum of 2.4 at the age of 50, as children become adults. After the age of 50, the number of adults declines, first as grown children leave home, and then through separation or death. By the age of 70 , the average household has 1.5 adults - i.e. every second household is composed of a single individual. The number of adults in the household over the life cycle is clearly an important determinant of household income, car ownership and car travel. As young adults form households, income increases and first, then perhaps second, cars are purchased and car travel increases. This is compounded as their children grow up and learn to drive - often contributing to the household income and obtaining cars of their own. Later, both car ownership and use decline, as adult children leave home taking their car with them or through the disposal of second cars, and finally predominantly through the death of a spouse.

The data on car travel and corresponding income data for the cohorts can be used to illustrate the relationship between income and car travel. Figure 3 shows the data for three of the cohorts. The vertical axis shows the car travel per household while the horizontal axis is real total household expenditures, which is used as a proxy for income. The earliest cohort shown, with the head born between 1911-1915, is representative of pensioner households. The head ages from 59 to 80 over the observed time period and both car travel and income are declining. The most recent cohort shown - 1961-65 - is an example of a relatively young household, with the head ageing from 20 and $30^{1}$. Both income and car travel are increasing rapidly. Comparing these two cohorts, it is apparent that the slope of the line indicating the car ownership - income relationship is greater for the increasing income case (1961-65) than it is for the decreasing income case (1911-15). Since the slope of the line is directly related to the magnitude of the income elasticity, this suggests that car travel responds more strongly to rising incomes than it does to falling incomes. Rising incomes lead to a higher car travel level, but when incomes fall car travel is not reduced correspondingly.

This asymmetry is clearly exemplified in the middle-aged cohort (1931-35), where the hysteresis loop is particularly apparent. Here, we follow the cohort as the age of the head increases from 35 to the age of 60 . Between the ages of 35 and 50, household income and car travel are increasing, while after the age of 50 or so both income and car travel begin to decline. But the same path is not followed. As income declines, car travel declines, but to a lesser degree than it rose as income increased. For each income level we have two rather than one level of car travel. There is no unique car-use-income relationship, rather a hysteresis loop. The explanation for this is a simple one: households have become accustomed to the convenience of car travel. Such car dependency is not easily reversed, so there is a tendency to maintain car ownership in spite of falling income.

\footnotetext{
1 This cohort is only observed in the surveys from 1983 onwards.
} 
Figure 3. Relationship between car travel and income, 1970-95. FES data.

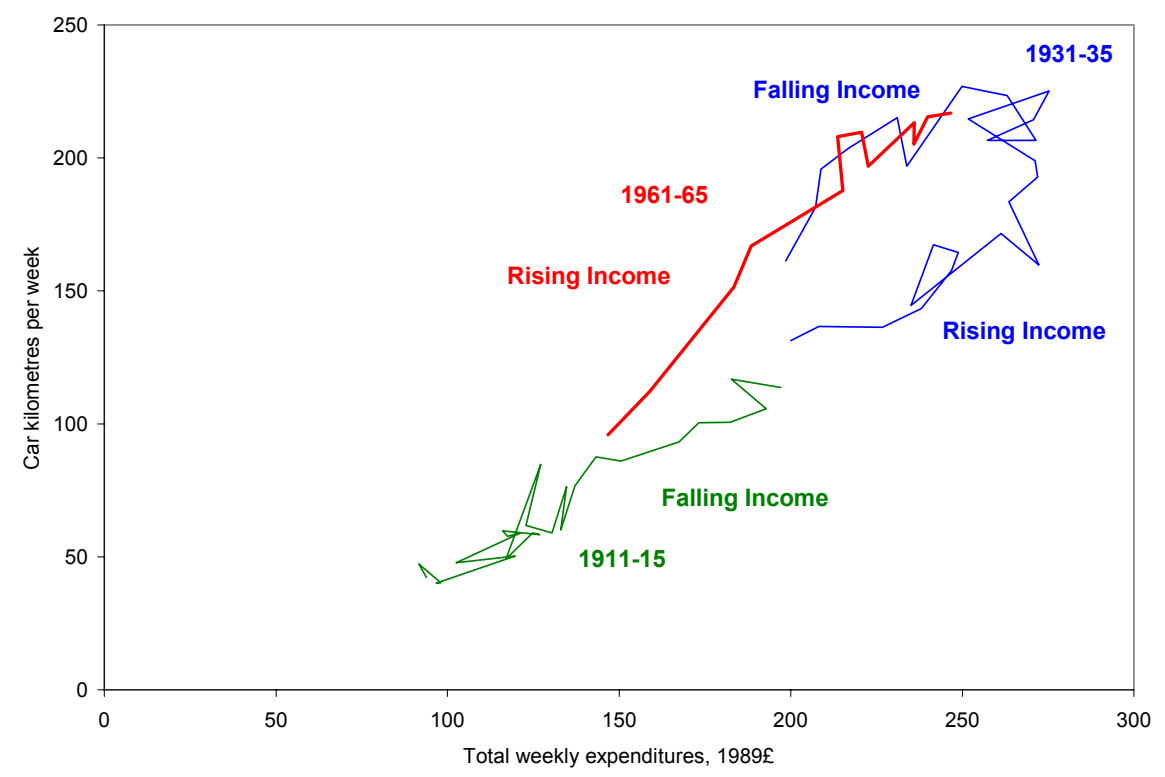

Apart from the data on car travel and income shown above, the average numbers of adults of driving age and children below this age for each cohort are obtained from the FES data. The survey, however, contains no information on prices. These data must therefore be obtained from other sources, and in the absence of more detailed price information, we are forced to resort to national average price indices, which are assumed to be identical for all cohorts for a given year.

\section{Model Specification}

\subsection{The car travel model}

Following our earlier work on car ownership, the analysis of household car travel is carried out on the basis of a simple dynamic model. It is assumed that the desired car travel, $C_{i, t}^{*}$ (in kms per week), for cohort $i$ in period $t$ can be expressed as:

$$
C_{i, t}^{*}=f\left(Y_{i, t}, A_{i, t}, K_{i, t}, P_{t}, F_{t}, G_{i}\right)
$$

where $Y_{i, t}, A_{i, t}$, and $K_{i, t}$ are total household expenditures (in £s per week, used a proxy for income), the number of adults of driving age and the number of children per household included in cohort $i$ in period $t . P_{t}$ is an index of real car purchase prices, which includes both new and second-hand cars, and $F_{t}$ is a consumption share weighted index of the real prices of petrol and diesel. Although these prices vary over time, they are assumed to be the same for all cohorts. This should be a good approximation since the number of households making up each cohort is relatively large. Finally, $G_{i}$ is a cohort-specific generation effect.

Lags in adjustment of car travel to changes in the explanatory variables are specified by a simple partial adjustment mechanism, so that actual car travel, $C_{i, t}$ for each cohort $i$ in period $t$ can be expressed as:

$$
C_{i, t}=\theta f\left(Y_{i, t}, A_{i, t}, K_{i, t}, P_{t}, F_{t}, G_{i}\right)+(1-\theta) C_{i, t-1}
$$


where $C_{i, t-1}$ is car ownership in period $t-1$ and $\theta$ is the adjustment parameter.

As in previous work a number of different functional relationships are examined, which have different implications for the resulting elasticities. These are:

$$
\begin{aligned}
& \text { linear } C_{i, t}=\alpha_{i}+\beta_{Y} Y_{i, t}+\beta_{A} A_{i, t}+\beta_{K} K_{i, t}+\beta_{P} P_{t}+\beta_{F} F_{t}+\phi C_{i, t-1}+u_{i, t} \\
& \quad \text { double-logarithmic } \\
& \quad \operatorname{Ln} C_{i, t}=\alpha_{i}+\beta_{Y} \operatorname{Ln} Y_{i, t}+\beta_{A} L n A_{i, t}+\beta_{K} \operatorname{Ln} K_{i, t}+\beta_{P} \operatorname{Ln} P_{t}+\beta_{F} F_{t}+\phi \operatorname{Ln} C_{i, t-1}+u_{i, t} \\
& \text { semi-logarithmic } \\
& \quad C_{i, t}=\alpha_{i}+\beta_{Y} \operatorname{Ln} Y_{i, t}+\beta_{A} A_{i, t}+\beta_{K} K_{i, t}+\beta_{P} P_{t}+\beta_{F} F_{t}+\phi C_{i, t-1}+u_{i, t} .
\end{aligned}
$$

In the linear model the price (income) elasticities increase with increasing price (income) and decrease with increasing car travel. The double-logarithmic model assumes a constant elasticity for all price, income and car travel levels. The semi-log model is similar to the linear model with the exception that the income elasticity declines with increasing car travel. This seems most appropriate as it takes into account saturation: at higher levels of car travel, the effects of increasing income diminish.

The $\alpha_{i}$ are cohort-specific intercept terms relating to the generation effects, $G_{i}, \phi=$ 1- $\theta$, and $u_{i, t}$ are random error terms, representing differences between cohorts not explicitly included in the model. Since the cohort observations are averages of the individual households included in each cohort, these can be considered as error-ridden measurements of the population cohort means, so that errors-in-variables techniques are required to yield a consistent estimator (see Deaton, 1985) However, as shown by Verbeek and Nijman (1992), when the cohort size is fairly large (at least over 100 individuals) and the time variation in the cohort means is sufficiently large, the bias in the standard fixed effects estimator will be small so that measurement-error problem can be ignored. This is the approach taken in this study.

Further, if the numbers of households in each cohort and for every time period are not the same, the disturbance term $u_{i, t}$ will be heteroskedastic so that the estimates of the coefficients will not be efficient. This heteroskedasticity can be corrected for by weighting the cohort observations with the square root of the number of households making up each cohort. Finally, we assume the $u_{i, t}$ are not correlated either between cohorts or over time. ${ }^{2}$

The short-run elasticities are obtained from the coefficients, $\beta$, while the long-run elasticities are obtained as the short-run values divided by $(1-\phi)$.

\subsection{Asymmetric Specification}

Possible difference in response to rising and falling income is examined based on a method used in Dargay and Gately (1997) to analyse the issue of price-reversibility. This is done by decomposing the income variable (or the log of income) into two monotonic variables: the cumulating series of income rises, $Y_{i, t}^{R}$, which is non-negative and nondecreasing, and the cumulating series of income falls, $Y_{i, t}^{F}$, which is non-positive and nonincreasing. These are defined as follows:

$$
Y_{i, t}^{R}=\sum_{t=0}^{T} \max \left\{0, Y_{i, t}-Y_{i, t-1}\right\}
$$

2 If the error terms are serially correlated the estimator used will be inconsistent because of the inclusion of the lagged dependent variable. However, arlier work suggests that allowing for this has little effect on the estimated parameters. Further work will consider a more general error structure. 


$$
Y_{i, t}^{F}=\sum_{t=0}^{T} \min \left\{0, Y_{i, t}-Y_{i, t-1}\right\}
$$

where

$$
Y_{i, t}=Y_{i, 0}+Y_{i, t}^{R}+Y_{i, t}^{F} .
$$

The asymmetric specification is obtained by replacing the original income variable in equations (1) with $Y_{i, t}^{R}$ and $Y_{i, t}^{F}$ or $\operatorname{Ln} Y_{i, t}^{R}$ and $\operatorname{Ln} Y_{i, t}^{F}$ as appropriate. For example, for the semi-log model we have the following asymmetric specification:

$$
C_{i, t}=\alpha_{i}+\beta_{Y R} \operatorname{Ln} Y_{i, t}^{R}+\beta_{Y F} \operatorname{Ln} Y_{i, t}^{F}+\beta_{A} A_{i, t}+\beta_{K} K_{i, t}+\beta_{P} P_{t}+\beta_{F} F_{t}+\phi C_{i, t-1}
$$

where $\beta_{Y R}$ and $\beta_{Y F}$ denote the response to rising and falling income, respectively. If $\beta_{Y R}>$ $(<) \beta_{Y F}$ the response of car travel to rising income is greater than (less then) that to falling income. If $\beta_{Y R}=\beta_{Y F}$ the response of car travel will be the same to rising and to falling income, and the model will revert to the symmetric specification.

\section{Estimation Results}

The models described above are estimated from the cohort data described earlier. There are 16 cohorts with an observation period ranging from 1976 to $1995^{3}$. Only those cohort-year observations containing at least 100 households are included in the estimation to assure that the sample cohort data are reasonable estimates of the population cohorts. In all, we have 256 cohort observations with an average of 500 household observations.

Choice of functional form is based on the statistical tests shown in Table 1. These are based on the asymmetric specifications for the three functional forms in equations (1). Since the linear and semi-log models have the same dependent variable and same number of regressors, the choice between them can be based on the log likelihood values shown in the table. We see that the log likelihood value for the semi-log model (-950.46) is slightly larger than that for the linear model (-958.48), so that the semi-log model explains the data better and is thus preferred statistically. Comparison of these models with the double-log model is not as straightforward since the dependent variables are not the same. A suitable procedure is the PE Test developed by MacKinnon, White and Davidson (1983). This takes the form of two t-statistics, one for each of the two models being compared. A significant value in only one of the equations unequivocally rejects that model in favour of the other. A significant value for both equations implies that both models are to be rejected, while a significant value for neither equation implies that no choice can be made on the basis of the test. From the table, we see that the PE tests reject the double-log model in favour of both the linear and semi-log models. Thus on the basis of the statistical tests, the semi-log model is the preferred. This model also makes the most sense economically: the income elasticity declines with increasing car ownership, so that saturation can be accounted for explicitly. However, judging from the $\overline{\mathrm{R}}^{2}$ values, all specifications explain the data very well.

The tests for symmetry - i.e. equivalent response to rising and falling income - are shown at the bottom of the table. This entails testing the significance of the difference between the coefficients of the decomposed income variables. From the t-test we see that the hypothesis of symmetry is not rejected for the linear and double-log models. However, for the preferred functional specification, the semi-log model, symmetry is rejected with at least $97 \%$ confidence, thus strongly supporting asymmetric response to income changes.

\footnotetext{
3 Data for 1970-75 are excluded because of missing data for some variables.
} 
Table 1. Tests for functional form and asymmetric income response.

\begin{tabular}{|c|c|c|c|c|}
\hline & Linear & Double-log & Semi-log & Test result \\
\hline Adjusted $\mathrm{R}^{2}$ & 0.988 & 0.997 & 0.989 & \\
\hline Log likelihood & -958.48 & 257.70 & -950.46 & \\
\hline Tests for functional form & & & & \\
\hline Linear vs double-log & $-1.50(0.14)$ & & & Reject double-log \\
\hline PE test: t-statistic ( $p$-value) & & $4.36(0.00)$ & & in favour of linear \\
\hline Linear vs. semi-log & & & & Reject linear in \\
\hline Compare Log likelihood & 05818 & & 05016 & favour of semi- \\
\hline Double-log vs. semi-log & & & & \\
\hline PE test: t-statistic ( $p$-value) & & $5.51(0.00)$ & $-1.87(0.06)$ & $\begin{array}{l}\text { Reject double-log } \\
\text { in favour of semi- } \\
\text { log }\end{array}$ \\
\hline Test for symmetry & & & & \\
\hline $\begin{array}{l}\left.\mathrm{H}_{0}: \beta \text { YR }=\beta \text { YF ( } p \text {-value }\right) \\
\text { Test result: Symmetry }\end{array}$ & $\begin{array}{l}-1.42(0.16) \\
\text { not reiected }\end{array}$ & $\begin{array}{l}0.92(0.30) \\
\text { not reiected }\end{array}$ & $\begin{array}{l}2.12(0.03) \\
\text { reiected }\end{array}$ & \\
\hline
\end{tabular}

The estimation results for the preferred asymmetric semi-log model are presented in Table 2. In all cases, the estimated coefficients are highly significant and of the expected signs. Income has a positive influence on car travel, and the effect of rising income is greater than that of falling income. Prices have the expected negative effect: as the costs of car ownership and motor fuel increases, car travel declines. An increasing number of adults in the household tends to increase car travel, while an increase in the number of children appears to reduce it. The estimates imply that an additional adult increases household car travel by about a third, while and additional child reduces it by around $10 \%$. The coefficient of the lagged car travel variable is of a reasonable order of magnitude and highly significant, confirming the validity of the dynamic specification. Car travel does not adjust instantaneously to changes in the explanatory variables, but adjustment is relatively swift, with $75 \%$ occurring within one year, while full adjustment $(99 \%)$ occurs in just over 3 years.

The generation effects - the $\alpha \mathrm{s}$ - are not at all clear-cut. We would expect these to increase from the eldest to the more recent generations, as car travel becomes more widespread. Instead, they appear to level off rather quickly and even to decline for the more recent generations. However, the standard errors are very large so that there is little statistically significant difference between them. Despite this, deletion of the generation (or fixed) effects is rejected by statistical tests. ${ }^{4}$ It appears that differences in car travel among generations noted earlier are explained largely by differences in income and prices. Income itself shows a generation effect, with successive generations having higher real incomes than previous generations. Motoring costs have also declined over the period. From this and other studies, it appears that the pure generation effects are reduced as more explanatory variables are included in the model.

${ }^{4}$ A random effect model is also estimated, but is rejected in favour of the fixedeffects model. 
Table 2. Estimates of household car travel model. Dependent variable: car travel in kms. per week.

\begin{tabular}{|c|c|c|c|}
\hline & Coefficient & Standard error & P-value \\
\hline$\phi \quad$ Car travel (t-1) & 0.25 & 0.05 & 0.000 \\
\hline$\beta_{Y R}$ Rising Income & 135.8 & 13.7 & 0.000 \\
\hline$\beta_{Y F}$ Falling Income & 106.8 & 15.0 & 0.000 \\
\hline$\beta_{P} \quad$ Car Purchase Costs & -63.6 & 14.6 & 0.000 \\
\hline$\beta_{F} \quad$ Motor Fuel Price & -15.3 & 5.5 & 0.005 \\
\hline$\beta_{A}$ Adults & 51.4 & 11.2 & 0.000 \\
\hline $\begin{array}{l}\beta_{K} \text { Children } \\
\text { Generation effects }\end{array}$ & -14.5 & 2.9 & 0.000 \\
\hline$\alpha_{1}$ before 1900 & 51.2 & 26.5 & 0.054 \\
\hline$\alpha_{2} \quad 1901-1905$ & 55.3 & 27.4 & 0.045 \\
\hline$\alpha_{3} \quad 1906-1910$ & 86.2 & 28.8 & 0.003 \\
\hline$\alpha_{4} \quad 1911-1915$ & 96.7 & 30.8 & 0.002 \\
\hline$\alpha_{5} \quad 1916-1920$ & 104.8 & 31.5 & 0.001 \\
\hline$\alpha_{6} \quad 1921-1925$ & 108.6 & 31.3 & 0.001 \\
\hline$\alpha_{7} \quad 1926-1930$ & 98.1 & 31.4 & 0.002 \\
\hline$\alpha_{8} \quad 1931-1935$ & 92.1 & 30.6 & 0.003 \\
\hline$\alpha_{9} \quad 1936-1940$ & 96.2 & 30.1 & 0.002 \\
\hline$\alpha_{10} 1941-1945$ & 108.2 & 29.1 & 0.000 \\
\hline$\alpha_{11} 1946-1950$ & 101.4 & 29.8 & 0.001 \\
\hline$\alpha_{12} 1951-1955$ & 84.4 & 27.9 & 0.003 \\
\hline$\alpha_{13} 1956-1960$ & 95.2 & 25.6 & 0.000 \\
\hline$\alpha_{14} 1961-1965$ & 90.6 & 24.3 & 0.000 \\
\hline$\alpha_{15} 1966-1970$ & 43.2 & 23.3 & 0.065 \\
\hline$\alpha_{16} 1971-1975$ & 57.6 & 25.6 & 0.025 \\
\hline$\overline{\mathrm{R}}^{2}$ & 0.989 & Observations & 256 \\
\hline Log Likelihood & -950.46 & & \\
\hline S.E. of regression & 10.39 & Mean dep. Var. & 155.15 \\
\hline
\end{tabular}

The income and cost elasticities resulting from the model are shown in the first two columns of Table 3. As mentioned earlier, these are not constant with the semi-log model. The income elasticities are inversely related to the level of car travel, while the cost elasticity declines with increasing car travel and increases at higher prices. The elasticities shown are calculated at mean car travel (165 kms per week) and prices in 1995.

Table 3. Income and Cost Elasticities of Car Travel Calculated at Mean Values for 1995 and Adjustment Parameters

\begin{tabular}{|c|c|c|c|c|c|}
\hline & \multicolumn{2}{|c|}{$\begin{array}{l}\text { Semi-log } \\
\text { asymmetric }\end{array}$} & $\begin{array}{l}\text { Semi-log } \\
\text { symmetric }\end{array}$ & $\begin{array}{r}\text { Linear } \\
\text { symmetric }\end{array}$ & $\begin{array}{l}\text { Double-log } \\
\text { symmetric }\end{array}$ \\
\hline & Short run & Long run & Long run & Long run & Long run \\
\hline Rising Income & 0.83 & 1.09 & 1.02 & 0.98 & 1.12 \\
\hline Falling Income & 0.65 & 0.86 & “ “ & “ “ & “ “ \\
\hline Car Purchase Costs & -0.35 & -0.46 & -0.62 & -0.50 & -0.43 \\
\hline Motor Fuel Prices & -0.10 & -0.14 & -0.18 & -0.14 & -0.11 \\
\hline Adjustment parameter & \multicolumn{2}{|c|}{0.75} & 0.74 & 0.67 & 0.83 \\
\hline
\end{tabular}

The estimated income elasticities are in line with those obtained in other studies. However, there is a difference in the elasticity for rising and falling income. A percentage rise in income increases car travel by $1.09 \%$ in the long run, but when income falls by $1 \%$ 
car travel is reduced only by $0.86 \%$. Thus a rise in income followed by an equivalent fall does not return car travel to its original level. Instead we have a situation of hysteresis. In addition, the functional specification implies that the income elasticity has declined over time as car travel increased and that it will continue to do so until saturation is reached.

The functional specification used implies that the cost elasticity declines (in absolute value) as car travel increases, and is greater at higher price levels. We find that car travel is far more sensitive to car purchase costs (with a long-run elasticity of -0.46) than it is to fuel prices (a long-run elasticity of -0.14). The elasticity with respect to car purchase costs is a similar order of magnitude to those obtained from aggregate time-series studies for the UK, while the fuel price elasticity is smaller. Goodwin et al. (2004) in a survey of the literature cites a consensus value for the elasticity of traffic levels with respect to the fuel price to be on the order of -0.3 in the long run. According to our estimates, such values would only apply at very low car travel levels or prices double those of today. From these results, it follows that it would take a substantial rise in petrol prices to have a significant effect on motoring.

Although the asymmetric semi-log model was found to be statistically preferred to the linear and double-log specifications, we recall that the evidence was rather weak and that symmetry was not rejected for the linear and double-log models. In the remaining columns of Table 3 the long-run elasticities from the different models are compared. We see that the imposition of symmetry in the semi-log model results in a long-run income elasticity of 1.02 , i.e. between those obtained for rising and falling income from the asymmetric model. Both price elasticities are slightly greater in the symmetric model, but the difference is not statistically significant, and the adjustment parameters are nearly identical. For comparison, the next two columns show the elasticities for the symmetric versions of the linear and double-log models (recall we found no indication of asymmetry with these models). In general, the variation in the elasticities obtained with the different models for 1995 is not very great.

Table 4 compares the long-run elasticities for car travel with those obtained for car ownership using the same cohort data and model forms. The first set of results (columns 1 and 2) is based on the model described earlier. On the basis of statistical tests the semi-log model is also the preferred for car ownership, but symmetric income response is rejected for all three functional specifications. The resulting income and price elasticities for car ownership (column 2) are smaller than those relating to car travel, and the speed of adjustment is slower.

These results can also be compared with those for car ownership reported in Dargay (2001) using the same cohort data (column 4). The model is slightly different in that it also includes life-cycle variables ( 6 dummy variables defined in terms of 10 year age bands for the head of the household). It was found that for car ownership, the semi-log model was the preferred functional specification and that symmetry was rejected for all functional forms. Tests based on the same models estimated for car travel (not shown here) also favour the semi-log model, but symmetric income response cannot be rejected for any of the functional forms. The resulting income and price elasticities for car travel (column 3) are greater than those for car ownership (column 4) and the speed of adjustment is quicker. This is the same result noted for the model excluding life-cycle effects. The resulting elasticities are also quite similar to those excluding life-cycle effects, the major difference being a reduction in the income elasticity. This is not surprising, as the life-cycle effects in the latter models are capturing some of the changes in car ownership and use over the life cycle which are attributed to income changes in the models excluding life-cycle effects.

The inclusion of the life-cycle dummies appears to make less difference for car ownership than for car travel. Not only is the difference between the elasticities for the two 
models greater for car travel, but also the conclusions concerning asymmetry are different. However, apart from for the income variables, the difference between the estimated parameters for prices, the number of adults and children and the lagged dependent variable for the two models are not significantly different from each other at the 5\% error level. This is true for both car ownership and car travel.

Choosing between the models including and excluding life-cycle dummies purely on the basis of statistical goodness of fit, favours the latter model for both car ownership and car travel. In terms of other statistical diagnostics, the models perform equally well. As shown in Dargay (2001) for car ownership, and confirmed by the estimates for car travel, the estimated life-cycle effects indicate an increase in car ownership and use as the head of the household ages, at least to the age group of 55 to 64, after which it levels off. This is not unreasonable, as the levelling off corresponds with pension age.

Table 4 Long-run income and cost elasticities for car ownership and car travel calculated at mean values for 1995 and adjustment parameters, semi-log models.

\begin{tabular}{lcccc}
\hline & $\begin{array}{c}(1) \\
\text { Car travel } \\
\text { asymmetric }\end{array}$ & $\begin{array}{c}(2) \\
\text { Car ownership } \\
\text { asymmetric }\end{array}$ & $\begin{array}{c}(3) \\
\text { Car travel } \\
\text { Life-cycle } \\
\text { symmetric }\end{array}$ & $\begin{array}{c}(4) \\
\text { Car ownership } \\
\text { Life-cycle } \\
\text { asymmetric }\end{array}$ \\
\hline Income & $0.86: 1.09$ & $0.55: 0.84$ & 0.85 & $0.45: 0.74$ \\
Car Purchase Costs & -0.46 & -0.12 & -0.54 & -0.13 \\
Motor Fuel Prices & -0.14 & -0.02 & -0.18 & $0^{*}$ \\
Adjustment parameter & 0.75 & 0.57 & 0.82 & 0.65 \\
\hline
\end{tabular}

*not significantly different from zero, and thus excluded.

The result that the income elasticity for car travel is higher than that for car ownership implies that increasing income leads to both greater car ownership and greater use per car. This seems contrary to the notion that multiple car ownership is associated with a lower mileage per car. However, the increasing car ownership noted in the sample has primarily been from zero to one car. As multiple car ownership increases, we would expect the income elasticity for car travel to fall to a level below that for car ownership. This effect cannot be examined with pseudo-panel data because individual households are not observed over time. Instead, real panel is required.

The finding that the degree of asymmetry of response to rising and falling income is greater (and more strongly supported) for car ownership than for car travel is also reasonable. As income falls, households may keep their cars, but they will use them less. The implied elasticities of use per car with respect to income are 0.25 and 0.11 for income increases and 0.31 and 0.40 for income reductions for the two models. Both suggest that use per car decreases more when income falls then it increases when income rises. When income rises, the demand for car travel increases, more cars are purchased and use per car increases. However, as car travel appears to be nearly symmetric to income changes, an equivalent fall in income will reduce the demand for car travel by nearly the same amount. But as the number of cars does not decrease when income falls to the same extent as it does when income rises (asymmetric response), the reduction in use per car resulting from the fall in income will be greater than the increase in use per car resulting from the rise in income.

That car travel responds more strongly to fuel prices than car ownership does is also as one might expect: the effect of fuel prices on car travel is largely the result of their impact on use per car, rather than on car ownership itself. The difference in elasticities for car ownership and car travel with respect to car purchase costs is not as easily explained. 
We would expect car prices to have their main effect on car ownership, with little impact on use per car. The results here suggest that this is not the case. Car ownership is relatively insensitive to car prices, with a long-run elasticity (in 1995) of about -0.1 . However, as car prices rise (fall), use per car declines (increases) much more substantially (with an implied long-run elasticity of -0.34 and -0.41 in the two models). An explanation for this may be that as cars become more (less) expensive, fixed costs per kilometre increase (decrease), so there will be a tendency for car use to decline (rise). The noted effect is, nevertheless, more substantial than might be expected.

Finally, the results suggest that car travel adjusts more quickly to changes in the explanatory variables then does car ownership. Since car travel is determined by car ownership and use per car, the total adjustment period for car travel must in reality be equal to the longer of the adjustment periods for car ownership and car use. We would expect use per car to adjust more quickly than car ownership, so that the adjustment period for car travel should be the same as that for car ownership. Similarly, the intertemporal pattern of adjustment for car travel should be the sum of the intertemporal response patterns for car ownership and use per car. If both car ownership and use per car follow geometrically declining adjustment patterns (as with the partial-adjustment specification assumed), but with car use having a more rapid speed of adjustment, the response of car travel will be concentrated in the periods just following the changes in the explanatory variables with the effects further on in time being relatively smaller. Thus the response pattern for car travel cannot also be geometrically declining, and the imposition of a geometrically declining lag structure (as done here) will necessarily result in a greater speed of adjustment than that for car ownership. This questions the dynamic specification used and suggests that less-restricted dynamic structures may produce more plausible results. Further work will address this issue.

\section{Conclusions}

From the cohort data constructed from the FES we have seen how household car travel increases over the life cycle up until the 'head' reaches about the age of 50 and declines thereafter. This pattern closely follows that of household income and the number of adults in the household over the life cycle. The data also show the diffusion process: motoring has become more prevalent in successive generations. Our model explains this process chiefly by increasing real income and the reduced cost of motoring.

There is some indication that the relationship between household income (expenditures) and car travel is not symmetric. However, the statistical evidence is not very strong and the conclusions are dependent on functional form and model specification. This finding is different from that for car ownership, where symmetry is strongly rejected for all functional forms and specifications estimated. For car ownership, the elasticity with respect to rising income is significantly and substantially greater than the elasticity with

respect to falling income. Rising income makes it easier for households to own cars, and once acquired, cars are not readily disposed of even if the economic consequences - in terms of alternative consumption foregone - are greater than previously, due to falling income. Car ownership is thus strongly associated with habit and resistance to change. Car travel, on the other hand, is somewhat less so.

The estimated elasticities indicate that car travel is sensitive to its cost, but not highly so. Car travel is more affected by car purchase costs than by fuel prices, implying that once obtained, cars are used despite rising variable costs for their use. This is not surprising since the marginal cost of car travel declines at higher utilisation. On the other hand, car ownership is more sensitive to car purchase costs than to fuel prices, as would be expected. 
The predominant impacts of both types of costs on car travel arise through their effects on use per car rather than on car ownership. As expected, the results confirm that car use responds more rapidly to changes in income and prices than does car ownership.

In general, the results suggest that it is easier to influence car use by policy measures than it is to influence car ownership. Car use responds more strongly and more quickly to prices and is less associated with resistance to change.

\section{Acknowledgements}

Funding for this project has been provided by the Economic and Social Research Council of the UK. Material from the Family Expenditure Survey is Crown copyright; has been provided by the Central Statistical Office through the ESRC Data Archive; and has been used by permission. Neither the CSO nor the ESRC Data Archive bears any responsibility for the analysis or interpretation of the data reported here.

\section{References}

Dargay, J., 2001, The effect of income on car ownership: evidence of asymmetry, Transportation Research Part A 35 807-821.

Dargay, J., 2002, Car ownership in rural and urban areas: a pseudo-panel analysis, Transportation Research, Part B 38 351-366..

Dargay, J., Gately, D., 1997, The demand for transportation fuels: imperfect price reversibility? Transportation Research, Part B: Methodological, Volume 31B, No. 1, February, pp 71-82.

Dargay, J., Madre, J-L., Berri, A., 2000, Car ownership dynamics as seen through the follow up of cohorts: a comparison of France and the UK, Transportation Research Record, No 1733.

Dargay, J., Vythoulkas, P., 1999, Estimation of a dynamic car ownership model: a pseudo panel approach, Journal of Transport Economics and Policy 33(3) 283-302.

Deaton, A (1985), Panel data from time-series of cross-sections, Journal of Econometrics 30, 109-126.

Goodwin, P. B., Dargay, J., Hanly, M., 2004, Elasticities Of Road Traffic And Fuel Consumption With Respect To Price And Income: A Review, Transport Reviews, forthcoming.

MacKinnon, J., White, H., Davidson, R., 1983, Tests for model specification in the presence of alternative hypotheses; some further results, Journal of Econometrics, 2153 70 .

Madre, J-L., 1990, Long term forecasting of car ownership and use, Developments in Dynamic and Activity Based Approaches to Travel Analysis (P Jones ed.), Gower Publishing, Oxford.

Verbeek, M., Nijman, T., 1990, Can cohort data be treated as genuine panel data?, in Panel Data Analysis (B Raj and B H Batalgi eds.), Physica-Verlag Heidelberg. 